\title{
Reply
}

\section{Sizing Up Science: A Reply to Fuller}

\author{
MIRIAM SOLOMON Temple University
}

\section{Introduction}

Fuller claims that epistemic properties of scientific activity are size-sensitive. Size is measured in terms of numbers of scientists and wealth of their material resources (e.g. funding, instrumentation, access to information). He states that when science gets much bigger, as it has this century, the epistemology of science changes: the "classical search for knowledge" ends (p. 8 ) and we move into a "post-epistemic society" (p. 10). Fuller claims that such "Big Science" (p. 4) is epistemologically at risk, and may fail to be science altogether. This provocative suggestion is worth considering, for the reasons he gives and for other reasons also.

Naturalistic considerations support the claim that human strategies for investigating the world may change as social and material conditions change. Scientific methods are not a priori. Different methods and policies will prove successful in different social and psychological situations, and for different problem domains. Availability of instruments and other experimental resources should also influence choices of method and direction of research.

I shall agree with Fuller that size belongs as a variable in epistemological accounts of science. I offer reasons to doubt that it is as pivotal a variable as he claims. I also respond to Fuller's suggestions for preventing Big Science from becoming the end of all science with some suggestions of my own.

\section{Epistemic Maladies and Epistemic Myths}

Much scientific work is large in scale and thus, in the present social conditions, dependent on support from the government, military, and industry. Grant applications are tailored to suit the ends of these institutions as well as, or instead of, socalled "internal" goals of science. Furthermore, most scientific work is fully accessible only to a relatively small group of scientists in a particular subspecialty; other scientists, as well as the general public, are regarded as "unqualified" to make evaluations.

Scientific work was not always this way. There was a time when many scientists with modest fortunes, generous friends or university affiliation could support their own experimental research (Harvey, Galileo, Newton, Priestley, Faraday, Darwin, Lyell) and relatively little technical expertise and background knowledge was needed to understand scientific controversies (e.g. the path of blood flow in the body, the Scientific Revolution, the Chemical Revolution, debates over the evolution of species and changes in the earth's crust).

Fuller writes that the increased need for major external funding, and the fragmentation of the scientific community into units with particular specialized knowledge are new maladies of science that are likely to inhibit scientific progress. He is joined by many working scientists weary 
of the constraints and pressures of grant administration or struggling with the demands of contributing and gaining recognition in a particular field. It is tempting to look back to a time when there was no Big Science, and think that things used to be epistemologically better. This is a myth, akin to many myths that weary commuters and consumers hold about preindustrialized societies.

There never was an "epistemic world" where scientific work was free from interests and biases that can be disruptive to the scientific enterprise. When scientists needed support for experimental work or simply living expenses, they had to negotiate the whims of royalty, aristocracy and university hierarchy. Their ideas were received and criticized in communities with entrenched ideologies. Personal factors such as pride, competitive spirit and responsiveness to peer pressure generally influence scientific decision making. Cognitive biases such as confirmation bias, overvaluation of salient and available information and belief perseverance also have pervasive effects on scientific thinking. Much new work in sociology and psychology of science documents the role of interests and biases in historical case studies of scientific change'. Inasmuch as human beings have done science in a social world, there cannot have been the "classical search for knowledge" (p. 8) that Fuller retrodicts.

Judging from his other writings, Fuller is quite aware of this work in history, sociology and psychology of science. It must be inferred that he has a special concern for the epistemological character of Big Science, that does not simply register the influence of "external" interests and the limited role of criticism. One possibility is that Fuller is claiming that Big Science is more influenced by biases and interests than Little Science, and that the biases and interests of Big Science exceed some threshold of epistemic toleration. If this is his view, it lacks evidence. It may be that increased specialization within science has raised the qualifications for participation in criticism, and thereby excludes many scientists and most of the public from scientific debate. It is also the case, however, that there are many more scientists, and perhaps as many are involved in each particular dispute as in the past (although not proportionately as many of the scientific community). Within subspecialties, scientists can get both criticism and recognition for their work. Peer review for journals and academic conferences for exchange of information and results are relatively new forums for criticism associated with the rise of Big Science. Standards of professional ethics - both academic freedom and academic honesty - are now part of the institution of science. For every epistemic step back that Big Science makes, it appears that there is also a (different) step forward. There is no reason to think-without more evidence-that Big Science is any less likely to "represent the structure of reality" (p. 6) ${ }^{2}$ than Little Science.

\section{Public Accountability}

In my view, Fuller's central concern is not the degree to which Big Science is biased and interested but the particular moral and political values it instantiates. When Fuller deplores the lack of "accountability" of Big Science he is especially concerned about the lack of public accountability and less concerned about the lack of criticism across the scientific community. Big Science fails to be accountable to the public because its interests are developed around the hands that feed itgovernment, the military, industry-rather than around the hands that need it for health care, technology and the environment, and are morally entitled to it. It also fails to be accountable to the public because increased specialization has brought with it an attitude of professional elitism that eschews criticism from outsiders, who are regarded as unqualified to judge. 
Fuller makes specific proposals for improving the public accountability of science. The incentive structure of science could be changed by having scientists wager with one another, in a public competition, about the results of a proposed plan of research. This would cut some of the strings to large funding institutions. The public could be involved in scientific disputes, through media coverage of staged debates between scientists. Just as audiences for sporting events engage in criticism of particular performances, they could make judgements of scientific merit.

Note that these are proposals for improving public accountability of science, and not obviously proposals for improving science. Fuller conflates the two, deliberately. It is his view that the moral and the epistemic cannot be separated (p. 7). Even if this view is true, however ${ }^{3}$, these morals and the various goals of the scientific enterprise can be separated.

Groups do not always correct for biases made by individuals; indeed, in some cases, they amplify bias. ${ }^{4}$ Furthermore, groups of non-experts are criticizing from a position of relative ignorance. Their general mechanisms for thinking may be, as Fuller says, the same as scientists' (p. 2), but it does not follow that their reasoning will be as good, because their background assumptions are less reliable.

Scientific work may or may not improve as a result of replacing the interests of large politicized institutions with the interests of individual humans; it is an empirical question, and one whose answer is relative to particular social situations. The marine research crucial to the development of plate tectonic theory was dependent on the resources of the U.S. Navy. The future of the supercollider project is dependent on the support of the NSF. It is difficult to see how either of these projects could be organized as a village industry around the human interests of most people. Other worthwhile scientific projects, however-perhaps less costly projects with more direct technolog- ical applications-might do better when governed by public interests. Fuller claims that scientists can always devise and then choose Little Science projects to answer scientific questions (p. 6). No doubt this is true in some cases and should be encouraged for reasons of economy, but it would be surprising if it were true in general.

It is just as much a choice to eschew large projects as it is to embrace them. Restricting the community to Little Science projects is no more desirable for the scientific enterprise than over-emphasizing Big Science. One possibility for reorganization is to centralize resources (e.g. through taxation) without centralizing power over distribution of these resources. Distribution could be decided upon by elected experts, or simply randomized. These suggestions (as Fuller's suggestions) are worth investigating for feasibility and results; the impact on the scientific enterprise cannot be known in advance.

Fuller's view that scientific disputes can be, and should be, made accessible to non-experts who can then influence outcomes is a refreshing and welcome challenge to the authority of scientists. Again, the feasibility and results of doing this cannot be known in advance or in general. As mentioned above, the worth of nonexpert criticism of science is not known. Spectator sports are hardly without problems caused by media coverage and public involvement; they are hardly the role models for science that Fuller suggests. A suggestion that Fuller does not consider in this paper is the contribution that expertise from humanistic fields can make to the scientific enterprise. For example, if scientific education included history, politics, ethics, philosophy and psychology of science (perhaps as a matter of public demand rather than governmental interference) scientific work might be more creative, tolerant of differences, critical of both trendiness and conservativeness and careful with issues of academic honesty. Most scientists have archaic views about scientific 
progress and scientific method, and it would be interesting to see whether and how their practices might change with education. Even this proposal needs to be tested in social context, and cannot be decided a priori.

\section{Conclusions}

Size is just one of the many variables that describe the scientific enterprise. Its epistemic import depends on the background social and political context, the internal organization of science into subgroups and the particular scientific problem under investigation. Big Science seems no less in danger of failing than
Little Science; they court epistemically equivalent although different dangers. The problems of each need to be separately investigated and addressed through assessments of the relative effectiveness of various policies and kinds of reasoning.

Fuller's criticisms of Big Science turn out to be more moral than epistemic. He objects to the control that large politicized institutions-especially the militaryhave on the distribution of scientific resources and thereby on the direction of scientific progress. I have argued that the alternatives to this that Fuller presentsand I supplement-are worth investigating, but there is no telling a priori what the impact on science will be. Only morals can be settled in advance.

\section{Notes}

1 See, for example, the work of Kuhn and more recent work in the Kuhnian tradition such as Harry Collins, Changing Order: Replication and Induction in Scientific Practice (Chicago: University of Chicago Press 1992 [1985]); Bruno Latour and Steve Woolgar, Laboratory Life: The Construction of Scientific Facts (Princeton, NJ: Princeton University Press 1986 [1979]); Steven Shapin and Simon Schaffer, Leviathan and the Air-Pump: Hobbes, Boyle and the Experimental Life (Princeton, NJ: Princeton University Press, 1985). The bibliography to Fuller's paper contains further examples.

2 This is Fuller's stated view of the goal of science, not mine. The same epistemological points can be made for other views of the goals of science, including my own view which is that empirical success (broadly construed) is the goal of scientific work.
3 Robert McCauley, "Epistemology in an Age of Cognitive Science," Philosophical Psychology $1: 2$ (1988) pp. 143-15I argues that the goals of science must be articulated in a general discussion of values. Although I do not agree with this view, it is widely held, and I grant it for the purposes of discussion here.

4 See, for example, G. Hill, "Group vs. Individual Performance: Are $\mathrm{N}+\mathrm{I}$ heads better than One?" Psychological Bulletin 91 (1982) pp. 517-539.

MIRIAM SOLOMON

DEPARTMENT OF PHILOSOPHY

TEMPLE UNIVERSITY

PHILADELPHIA, PA 19122 